\section{SOI: 1.1 /TAS DOI: 10.15863 /TAS International Scientific Journal Theoretical \& Applied Science}

\author{
p-ISSN: 2308-4944 (print) e-ISSN: 2409-0085 (online) \\ Year: $2017 \quad$ Issue: $11 \quad$ Volume: 55
}

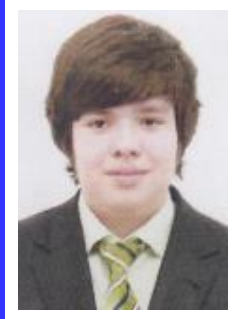

A.V. Chistilin

Master of the faculty "Public and financial control" at the Financial university under the Government of the Russian Federation

SECTION 19. Management. Marketing. Public administration.

\title{
THE ANAL YSIS OF THE STATE PROGRAM OF AGRICULTURE DEVELOPMENT AND REGULATION OF MARKETS OF AGRICULTURAL PRODUCTION, RAW MATERIALS AND FOOD FOR THE PERIOD OF 2013-2020
}

\begin{abstract}
The transition of Russia to the market system of management has entailed essential changes in conditions of economic activity in rural areas with everything that it implies: disorder of collective farms and state farms, privatization, impoverishment of peasants, unemployment rise, etc. Nowadays there is a necessity to improve the economic mechanism of development of regional subjects of agrarian management, to increase the efficiency of state participation through regional target programs of regulation. In this regard the state program of development of agriculture and regulation of markets of agricultural production, raw materials and food for the period of 2013 2020 is analyzed in this article.

Key words: Agriculture, import substitution, state support, agro-industrial complex.

Language: Russian

Citation: Chistilin AV (2017) THE ANALYSIS OF THE STATE PROGRAM OF AGRICULTURE DEVELOPMENT AND REGULATION OF MARKETS OF AGRICULTURAL PRODUCTION, RAW MATERIALS AND FOOD FOR THE PERIOD OF 2013-2020. ISJ Theoretical \& Applied Science, 11 (55): 9-15.

Soi: http://s-o-i.org/1.1/TAS-11-55-2 Doi: crossef https://dx.doi.org/10.15863/TAS.2017.11.55.2

\section{АНАЛИЗ ГОСУДАРСТВЕННОЙ ПРОГРАММЫ РАЗВИТИЯ СЕЛЬСКОГО ХОЗЯЙСТВА И РЕГУЛИРОВАНИЯ РЫНКОВ СЕЛЬСКОХОЗЯЙСТВЕННОЙ ПРОДУКЦИИ, СЫРЬЯ И ПРОДОВОЛЬСТВИЯ НА 2013-2020 ГОДЫ}

Аннотация: Переход России к рыночной системе хозяйствования повлек существенные изменения условий хозяйственной деятельности в сельской местности со всеми вытекающими отсюда последствиями: развал колхозов и совхозов, приватизация, обнищание крестьян, рост безработицы и т.д. В настоящее время назрела необходимость совершенствования экономического механизма развития региональных субъектов аграрного хозяйствования, повышения эффективности государственного участия через региональные целевые программы регулирования. В связи с этим в данной статье проанализирована государственная программа развития сельского хозяйства и регулирования рынков сельскохозяйственной продукиии, сырья и продовольствия на 2013-2020 годы.
\end{abstract}

Ключевые слова: Сельское хозяйство, импортозамещение, государственная поддержка, агропромышленный комплекс.

\section{Introduction}

На реализацию государственной программы, утвержденной постановлением правительства № 717 от 14.07.2012 г. предусмотрено выделение финансовых средств из федерального бюджета в 2013-2020 годы 3573379,9 млн. руб. (43,4\%) с разбивкой по годам. Прогнозная оценка бюджетных ассигнований из средств консолидированных бюджетов субъектов
Российской Федерации составляет 2375149,6 млн. руб. (28,8\%). из средств внебюджетных источников - 2279092.3 млн. руб. (27,7\%). Учитывая, что основная часть регионов страны дотационная и инвестиционная привлекательность АПК самая низкая, рассчитывать на финансирование программы в полном объеме уже с дня ее утверждения было нереально. К тому же федеральный бюджет 
составляет всего 43,4\%.

По расчету Министерства сельского хозяйства РФ до 2020 года дополнительно потребуется не менее 625,1 млрд. руб. Но уже в 2016 г. началось реальное сокращение финансирования из федерального бюджета. Так в первоначальном варианте предусматривалось 254,15 млрд. руб. фактически выделено 215 млрд. руб. Сокращение составило 39,15 млрд. руб. $(15,6 \%)$. Еще большее сокращение ожидается по другим источникам финансирования.

Примечательно, что в структуре средств федерального бюджета, выделенных в соответствии с Планом на государственную поддержку сельского хозяйства по состоянию на 1 января $2016 \quad$ г. $15.3 \%$ занимают бюрократические расходы, связанные с обеспечением реализации Государственной программы (для сравнения: расходы на поддержку растениеводства - 13\%). Удельный вес сельского хозяйства в общих расходах консолидированного бюджета страны остается на унизительно низком уровне и составляет всего немногим более 1\%. (в 2015 г. - 1,2\%.). Вызывает много нареканий и неясностей механизм «финансирования отдельных направлений программы в разрезе субъектов экономики.

\section{Materials and Methods}

Российский бизнес после реформы получил доступ к мировым достижениям в области сельского хозяйства. За годы реализации Национального проекта «Развитие АПК» (20062007 гг.) цепной индекс инвестиций в основной капитал сельскохозяйственных организаций вырос на 96\%. В период реализации Госпрограмм поддержки сельского хозяйства (2008-2012 и 2013-2020 гг.) индекс снизился до 36\% (2010 г.), затем увеличился до 65\% (2013 г.). В последние два года он вновь начал падать (рис. 1).

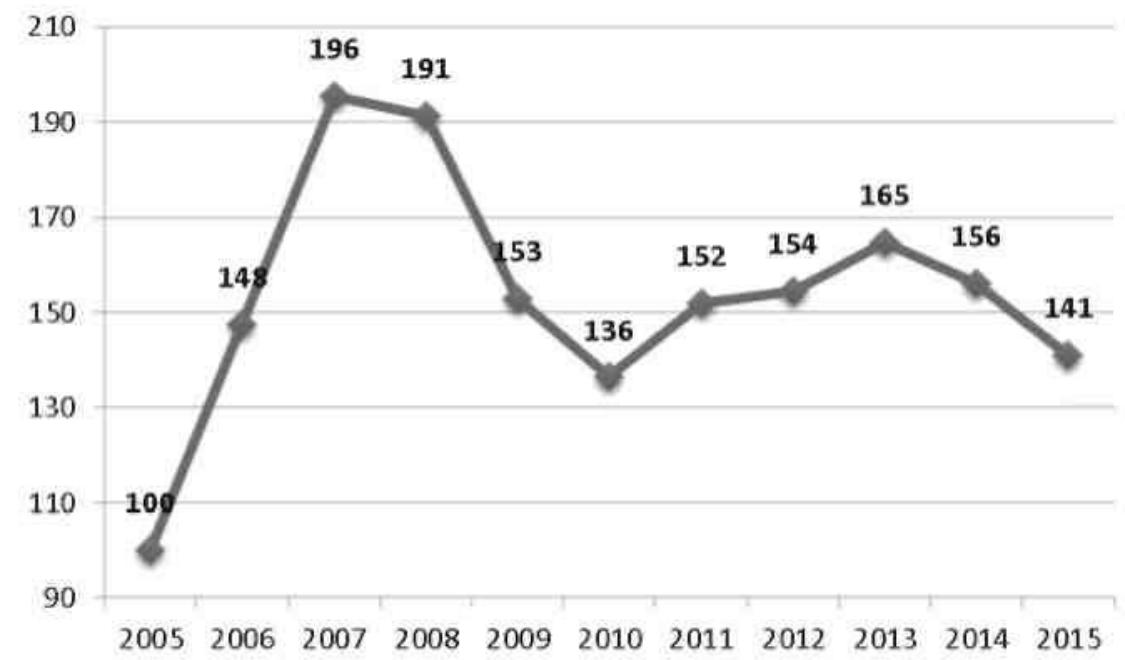

Рисунок 1 - Цепной индекс инвестиций в основной капитал сельскохозяйственных организаций Источник: ЕМИСС.

Несмотря на ограниченность инвестиционных ресурсов, за этот период российский бизнес, используя все зарубежные достижения научно-технического прогресса, провел в значительной мере техническую и технологическую модернизацию в сельском хозяйстве. Применение семян и гибридов зарубежной селекции по отдельным культурам приближалось к 100\% (табл. 1).

\section{Доля импортных семян в общем объеме их закупок, \%}

\begin{tabular}{|l|c|c|}
\hline & $\mathbf{2 0 1 3}$ & $\mathbf{2 0 1 6}$ (1-е полугодие) \\
\hline Овощи & 66 & 23 \\
\hline Кукуруза & 43 & 28 \\
\hline Подсолнечник & 46 & 44 \\
\hline Сахарная свекла & 96 & 69 \\
\hline Картофель & 62 & - \\
\hline
\end{tabular}

Источник: МСХ РФ. 
По данным MCX, комплектующие по теплицам были почти на 80\% импортными, по свиноводческим комплексам (включая оборудование убойного цеха) - на $75 \%$, по молочным комплексам - на 70\%. Доля импорта в используемых гербицидах в 2016 г. составила $56 \%$.

Применение зарубежных технологий способствовало существенному увеличению урожайности сельскохозяйственных культур (табл. 1). Справедливости ради следует заметить, что зерновые культуры выращиваются преимущественно из российских семян.

Продуктивность молочных коров выросла в CXO с 4,3 т в 2011 г. до 5,1 т в 2015 г., а в 2016 г. составила 5,3 т (оценка), сократились расходы кормов на килограмм мяса свиней и птицы в 2 раза. Российские свинокомплексы и птицефабрики по эффективности не уступают аналогичным фермам в развитых странах. Таким образом, на рост производства повлияла технологическая модернизация сельского хозяйства, осуществляемая при государственной поддержке.

В 2016 г. рост в сельском хозяйстве России продолжился. Как показал анализ, развитие было нацелено на повышение уровня удовлетворения потребностей населения страны в продовольствии, на обеспечение продовольственной независимости России путем замещения импортной продукции на аналогичную отечественную, на экспансию на мировые рынки зерна и растительного масла.

Из изложенного можно сделать вывод, что

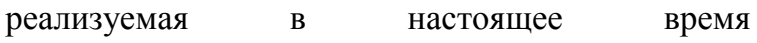
агропродовольственная политика не является эффективным инструментом обеспечения продовольственной безопасности в региональном разрезе, так как ставит субъекты РФ в неравное положение. Разные возможности финансирования из региональных бюджетов, причем преимущественно мер «желтой» корзины, препятствует развитию национального продовольственного рынка. Поэтому требуется четкое распределение полномочий между федеральным и региональным уровнями в осуществлении государственной поддержки сельского хозяйства, выравнивание бюджетной обеспеченности поддержки региональных АПК. создание условий для конкурентного их развития. [6, с. 15] Еще в большей степени наблюдается дифференциация выделяемых федеральных средств на реализацию ФЦП «Устойчивое развитие сельских территорий на 2014-2017 годы и на период до 2020 года», что свидетельствует о незначительном размере выделяемых средств в расчете на одного сельского жителя и значительной их дифференциации по регионам России (от 19\% до 427\%) Как следствие в дотационных регионах уровень жизни снижается в разы. При данном подходе депрессивные регионы не смогут самостоятельно развивать сельскохозяйственные территории, так как им приходится рассчитывать на собственные бюджетные средства, (которых просто нет) и внебюджетные источники. В результате социально-экономическая ситуация на селе остается сложной и в первую очередь в дотационных регионах.

Выделяемые субсидии из федерального бюджета на условиях софинансирования лишь усугубляют социальную ситуацию и увеличивают разрыв в уровне развития сельских поселений. Полагаем, что на обустройство жилья из федерального бюджета должны выделяться средства в расчете на сельского жителя одинаковыми без дифференциации. В противном случае продолжится дальнейшее опустынивание сельских территорий и углубление дифференциации экономического развития территорий и социальной среды. Известно, что сельское хозяйство всегда обеспечивало трудовыми ресурсами не только село, но и города. Сейчас же воспроизводство населения прекратилось не только в городах, но и на селе. За годы реформ численность сельского населения уменьшилась на 2 млн. чел.

Таким образом, современный этап развития мировой экономики характеризуется достаточно высокой динамичностью, противоречивостью и неоднозначностью. России, которая является частью и одним из лидеров этого процесса, необходимо ориентироваться в нем, тем более в условиях ограничения доступа к западным финансовым и технологическим источникам, резкого падения цен на нефть и другие углеводороды, политического и экономического ограничения во взаимодействии отечественных и зарубежных компаний для реализации совместных бизнес-проектов. В результате жестких внешних вызовов произошла девальвация национальной валюты, ускоренная инфляция, критических размеров достиг отток капитала, что привело к бюджетному дефициту и т.д.

В связи с этим, возникают определенные угрозы в отечественном сельском хозяйстве:

$\square$ отставание, а затем и устойчивая неразвитость собственного сельхозпроизводства;

$\square$ зависимость от импорта продовольствия, сельхозтехники, технологий;

$\square$ снижение качества жизни населения;

$\square$ неконкурентоспособность отечественных продуктов на внутреннем и внешнем рынках. И, как следствие, - потеря лидирующих позиций на мировом агрорынке.

Для этого необходима реализация определенной стратегии в аграрной политике. 
Особенность стратегии аграрной политики, по мнению авторов, в сложившейся внутренней и внешней экономической ситуации должна выражаться в следующем:

$\square$ в аграрном секторе необходимо обеспечить процесс импортозамещения как в краткосрочном, так и в долгосрочном периоде;

$\square$ реализация этого процесса невозможна без широкой поддержки государства;

$\square$ государство, в свою очередь, должно активно способствовать развитию агропромышленного комплекса (АПК), главными задачами которого являются повышение качества жизни населения, соединение науки с производством в сельскохозяйственном секторе, повышение инвестиционной и инновационной активности.

Аграрная политика, как известно, является составной частью государственной экономической политики. В настоящее время ее стратегия и приоритеты должны обеспечивать доходность сельского хозяйства. Рыночные реформы в аграрном секторе, их дальнейшее углубление предполагают совершенствование рыночных форм и методов хозяйствования.

Стратегию аграрной политики следует непосредственно связывать с развитием аграрной сферы отечественной экономики как основы продовольственного обеспечения населения. Базовой основой реализации стратегии в сельском хозяйстве является то, что Россия по основным видам ресурсов: производственным, земельным, трудовым, вполне самодостаточна. Однако общественный ресурсный потенциал не всегда рационально используется: аграрная сфера, не смотря на ее многофункциональный характер, не получала, например, приоритетного внимания со стороны государства. Являясь системообразующей структурой национальной экономики, аграрная сфера призвана формировать не только национальный, но и мировой агропродовольственный рынок, обеспечивать тем самым экономическую и продовольственную независимость, продовольственную безопасность страны, что является, в конечном счете, наиважнейшим фактором целостности и суверенитета государства.

Значимость развития аграрного сектора связана еще и с экономическими санкциями, введенными в 2014 году. В августе 2014 года в ответ на введенные санкции Россия также ввела запрет на импорт ряда продовольственных товаров: рыбы и морепродуктов, овощей, фруктов, орехов, молока и молочных продуктов, a также мяса птицы, говядины и свинины. Западные секторальные санкции привели к снижению доли российской продукции на мировом рынке. В этих условиях основные усилия государства должны быть нацелены на реализацию импортозамещающей политики не только в краткосрочном, но и долгосрочном периодах.

Выработка стратегии в аграрном секторе стала одной из основных государственных задач. Решить поставленную задачу может импортозамещение - целостная система, затрагивающая все сферы агропромышленного производства: производство средств производства для сельского хозяйства, производство и переработка сельскохозяйственной продукции, наука и управление.

Остановимся на некоторых моментах импортозамещения.

Импортозамещение

предполагает реструктуризацию национальной экономики или отдельных ее отраслей (например, сельское хозяйство), цель которой исключить импортную зависимость, а недостающие товары производить самостоятельно. Если импортозамещение рассматривается как обязательный элемент экономической стратегии, то это непременно приведет к исключению данной экономики из системы международного разделения труда, то есть к самоизоляции; и в конечном итоге - к экономической стагнации. Но, если снижение импорта обусловлено политическими причинами с использованием финансово -экономических рычагов одной страны (стран) по отношению к другой, то необходима разработка определенной стратегии импортозамещения, главная цель которой - не допустить экономического отставания, не потерять свои позиции на мировом рынке, при этом сохраняя имеющиеся ресурсы. Чтобы достичь желаемых результатов, необходимо четкое, поэтапное выполнение основных позиций импортозамещения. Импортозамещение оправдано и эффективно лишь в условиях производства равных, а лучше больших объемов отечественного продовольствия объемам импортного. При этом качество отечественных товаров и цены на них не должны превышать соответствующие показатели аналогичных импортных продуктов. Следует отметить и положительные моменты этого процесса. В июле 2016 г. доля импорта в потреблении сократилась с 32,3 до $21,4 \%$, а доля экспорта в производстве увеличилась с 28,7 до $36,1 \%$. Индекс производства продукции сельского хозяйства в январе - августе 2016 г. по сравнению с аналогичным периодом 2015 г. составил 103,4\%. Росли темпы вывоза злаков - на $31,5 \%$, в том числе пшеницы - на $59,9 \%$; картофеля - на 51,9\%, сахара - сырца - на 57,4\%, чая - на $6,0 \%$; мяса свежего и мороженого в 3,5 раза. $[8$, с. 7$]$

Возможен вариант и ускоренного 
импортозамещения, но при этом цены на продовольствие могут резко подскочить. Угроза такой ситуации - в нехватке и несвоевременности поддержки села со стороны государства. Так, согласно Госпрограмме развития сельского хозяйства до 2020 г., первоначально планировалось выделить на ее реализацию в 2015-2020 гг. 1186 млрд. руб., затем эта сумма возросла до 1760 млрд., а требуется, согласно расчетам, 2795 млрд. руб.

Решить проблему импортозамещения в целом в аграрном секторе без участия государства не представляется возможным: государство имеет только ему присущие инструменты воздействия (достаточные финансовые средства, законодательную, таможенную, налоговую системы, другие государственные структуры), с помощью которых можно воздействовать на процесс импортозамещения.

Надо признать: антироссийские санкции выявили слабость российской экономики, построенной на экспорте углеводородного сырья. Как выяснилось, основой и отечественного производства, в том числе сельскохозяйственного оказались в основном импортная техника, технологии и комплектующие. Например, около половины закупок племенного скота и сельхозтехники - это импорт. Такая ситуация создает угрозу национальной независимости. Ученые - аграрники справедливо считают, что важным элементом проведения аграрной политики в обеспечении продовольственной безопасности, является регулирование продовольственных рынков путем закупок продукции и продовольственных интервенций. [5, c. 643] Данная позиция отражена в Постановлении Правительства РФ от 05 октября 2016 г. № 1003.

Во внешнеэкономическом пространстве государственная политика должна способствовать эффективной реализации международного разделения труда в сфере продовольствия с тем, чтобы не допускать критической зависимости от импорта продовольствия.

Однако, в настоящее время можно выделить ряд продуктов, потребность в которых покрывается за счет собственного производства мясо свиней и птицы, овощи открытого грунта, зерно, сахар, растительное масло, яйца. Проблемой остается производство мяса крупного рогатого скота, молока и овощей закрытого грунта в необходимом объеме, к сожалению, задача среднесрочной перспективы.

Социально-экономическая активность любой национальной экономики во многом определяется уровнем и качеством жизни населения, степенью удовлетворения потребностей товарами и услугами. Одной из главных задач качества жизни российских граждан является повышение качества отечественных продуктов питания, не уступающих зарубежным аналогам, а иногда и превосходящих последние. Проблема обеспечения достойного качества отечественной сельхозпродукции должна решаться совместными усилиями всех уровней управления: федеральных органов, отраслевых, предприятий, финансовых структур.

Поскольку качество жизни - это еще и сгусток объединенных сил науки и производства, в условиях эффективного хозяйствования оно должно способствовать экономии материалов, энергии, труда, снижению себестоимости производимых товаров, росту прибыли, высокому уровню развития оборудования и технологии, с помощью которых производятся сельхозпродукты. От этого зависит непосредственное качество самих товаров и услуг, а также степень удовлетворенности их потребления. Следовательно, важно субсидировать в производство исключительно инновационную технику и технологию, так как вложенные средства на начальном этапе (как правило, немалые), экономически выгодны: способствуют не только росту производительности труда, но и повышают конкурентоспособность сельхозпродуктов как на внутреннем, так и на мировом рынках.

Современный рынок подвержен, к сожалению, таким угрозам национальной продовольственной безопасности, как наличие чрезмерно высокой доли в расходах домохозяйств на приобретение продуктов питания. Уровень потребления основных отечественных продовольственных товаров не соответствует мировым стандартам для обеспечения активного и здорового образа жизни. Почти четверть жителей Российской Федерации тратит на продукты питания от 30,1 до $40 \%$ своих потребительских расходов, одна пятая - от 40,1 до 50\%. Для сравнения в США на приобретение продуктов питания приходится лишь $6,0 \%$ совокупных расходов домохозяйств, в Великобритании - 7,2\%, в Австралии - 8,7\%, Германии - 9,0\%, во Франции - 10,2\%, в Республике Корея - 11,1\%, в Японии - 11,3\%. Приведенные цифровые данные красноречиво говорят сами за себя. [4, с. 426]

Реализация импортозамещения не может быть не связана с созданием, развитием и эффективным функционированием отечественного АПК. Максимальную эффективность деятельности АПК можно достичь на основе серьезной государственной поддержки, развития межотраслевых отношений, 
внедрения инноваций собственных разработок, гарантированного объема закупок сельхозпродукции, паритета цен на сельхоз и промышленную продукцию, благоприятной кредитной системы под доступные проценты. Однако, до сих пор реализовать в полном соответствии с вышеперечисленными условиями работу АПК не представляется возможным. Стратегия аграрной политики как раз и предполагает реальное претворение в жизнь этих условий функционирования АПК. В настоящее время вызывает обеспокоенность в привлечении инвестиций в АПК уже в ближайшие годы: так, если в 2015 г. на реализацию этой программы было направлено 237 млрд. руб., то в 2016 г. - и того меньше - лишь 215 млрд. руб. На этом примере следует еще раз подчеркнуть о важности особого подхода к реализации стратегической программы в АПК, где необходимо не уменьшать, а увеличивать финансовые вложения.

Важной стороной в развитии АПК является привлекательность российского сельского хозяйства для инвесторов. Это серьезный источник для развития отрасли. Инвесторы только тогда будут вкладывать свои деньги в сельхозпроизводство, когда увидят эффективное формирование структуры сельскохозяйственного капитала, степень платежеспособности, ликвидности, рисков различного характера. Особенность инвестиций в сельском хозяйстве еще и в том, что инвестиции вкладываются не только непосредственно в сельскохозяйственный капитал, но еще и в объекты природы, где более длительные сроки окупаемости, а, следовательно, и более высокие риски в бизнесе.

Потребности сельскохозяйственных производителей обслуживает и финансовая сфера. Так, по состоянию на 1 сентября 2016 г. объем кредитов, выданных на проведение сезонных полевых работ составил 191 441,4 млн. руб., то есть 117,5\% к соответствующей дате 2015 г. Крупнейший банк России «ПАО - Сбербанк» выдал кредиты на 64 812,7 млн. руб. (увеличение - на 118,5\%; АО «Россельхозбанк» - 126628 млн. руб. (рост на $117,0 \%$ ).

Иностранные инвесторы также потянулись в российский АПК. По данным центра привлечения инвестиций, в регионы России, в 2016 г. в сельском хозяйстве РФ проектов с участием иностранных инвесторов насчитывалось на 30\% больше, чем в 2015 г. [1, с. 80] Следует согласиться, что рынок, безусловно, перспективный: велика емкость внутреннего рынка с одной стороны; и достаточно большие возможности экспорта в рамках международных экономических ассоциаций, например, Евразийского экономического союза, с другой стороны.

Еще одна «приманка» иностранных инвесторов - это падение курса рубля, сокращение реальных зарплат внутри страны. Однако не следует обольщаться растущими результатами в этой сфере. Российский АПК и сегодня остается дотируемым и без государственной поддержки ему не обойтись.

Bсе зависит не только от инвестиционной, но и инновационной деятельности, которая является основой структурной перестройки агропромышленного сектора. Необходимы современное оборудование и сельхозмашины, комплексы по переработке сельхоз сырья вплоть до готовой продукции. В 2016 года производство зерноуборочных комбайнов возросло на $45 \%$, тракторов для сельского и лесного хозяйства - на 23,5\%.9 В целом, можно сделать вывод о сложившейся системе государственной поддержки сельского хозяйства, развитии АПК как фактора обеспечения продовольственной безопасности.

\section{Conclusion}

Подводя итог, следует подчеркнуть, что стратегию аграрной политики невозможно реализовать в краткосрочном периоде. В условиях финансово-экономической ограниченности доступа к передовым технологиям и дешевым кредитам, России необходимо быть готовой к длительному периоду решения задач как на внутреннем, так и на внешнем продовольственных рынках. Важно в сложившейся ситуации искать и открывать новые рынки для экспорта товаров отечественного АПК.

Особенность стратегии аграрной политики, ее последовательные, поступательные шаги по реализации выражаются в положительных результатах процесса импортозамещения, широкой поддержке государства, многоплановом развитии АПК, серьезном повышении качества жизни населения, расширении инвестиционной и инновационной активности, участии в деятельности международных экономических союзов. Все это позволит нашей стране обеспечить свою продовольственную безопасность. Несмотря на финансовоэкономические трудности, Россия не должна упустить возможность быть одним из лидеров и занимать достойное место в мировой экономике. 


\begin{tabular}{l|lrl|l|ll} 
& ISRA (India) & $=\mathbf{1 . 3 4 4}$ & SIS (USA) & $=\mathbf{0 . 9 1 2}$ & ICV (Poland) & $=\mathbf{6 . 6 3 0}$ \\
Impact Factor: & ISI (Dubai, UAE) $=\mathbf{0 . 8 2 9}$ & PUHL (Russia) $=\mathbf{0 . 2 0 7}$ & PIF (India) & $=\mathbf{1 . 9 4 0}$ \\
& GIF (Australia) & $\mathbf{0 . 5 6 4}$ & ESJI (KZ) & $=3.860$ & IBI (India) & $=\mathbf{4 . 2 6 0}$
\end{tabular}

\section{References:}

1. Chepik O.V. (2017) Mehanizm programmnocelevogo podhoda kak instrument gosudarstvennogo upravlenija regionom // Potencial sovremennoj nauki. 2017. № 1 (27). p. 78-82.

2. Chernyj I.I.(2017) Rynok zemel'nyh resursov v Rossii: problemy i perspektivy // V sbornike: Vektor social'no-jekonomicheskogo razvitija i pravovogo obespechenija nacional'nyh jekonomicheskih sistem Mezhdunarodnaja nauchno-prakticheskaja konferencija. 2017. p. 268-272.

3. Lenkin S.L. (2016) Samofinansirovanie regionov Rossii cherez zemel'nuju ipoteku // Wschodnioeuropejskie Czasopismo Naukowe. 2016. T. 14. № 2. p. 60-65.

4. Molotkov Ju.M. (2016) Programmno-celevoj podhod kak osnova organizacionnoj modeli formirovanija i razvitija APK (na primere Severo-Bajkal'skogo rajona Burjatii) // Vyhod iz krizisa: razvitie jekonomiki i promyshlennosti. - $\mathrm{SPb}$ : Izdatel'stvo: Federal'noe gosudarstvennoe avtonomnoe obrazovatel'noe uchrezhdenie vysshego obrazovanija "Sankt-Peterburgskij politehnicheskij universitet Petra Velikogo" (Sankt-Peterburg), 2016. p. 415-446.
5. Percev S.V. (2016) Rossijskij rynok zemel'nyh resursov // V sbornike: Aktual'nye problemy agrarnoj nauki $i$ puti ih reshenija sbornik nauchnyh trudov. Kinel', 2016. p. 640-644.

6. Polushkina T.M. (2016) Povyshenie konkurentosposobnosti sel'skih territorij cherez razvitie organicheskih metodov hozjajstvovanija // Upravlenie jekonomicheskimi sistemami: jelektronnyj nauchnyj zhurnal. 2016. № 9 (91). p. 15.

7. Rajzberg B.A. (2017) Celevye programmy v sisteme gosudarstvennogo upravlenija jekonomikoj. - Moscow, 2017.

8. Sidorenko V., Mihajlushkin P., Presnjakov D. (2016) Sovremennye problemy i prioritety agrarnoj politiki Rossii // Mezhdunarodnyj sel'skohozjajstvennyj zhurnal. 2016. № 2. p. 69.

9. Smagina M.N. (2017) Upravlenie razvitiem regiona: programmno-celevoj podhod. Monografija / Tambov, 2017.

10. Sverdlov V.V. (2017) Problemy vnedrenija programmno-celevogo upravlenija // Novaja nauka: Problemy i perspektivy. 2017. T. 1. № 3. p. 132-136. 